\title{
Are we there yet? An analysis of visitor attitudes towards sustainability awareness raising initiatives
}

\author{
ÁGNES RAFFAY-DANYI* [D and KATALIN FORMADI (]
}

Institute of Business, University of Pannonia, Veszprem, Hungary

Received: June 15, 2021 - Revised manuscript received: January 17, 2022 • Accepted: January 24, 2022

Published online: February 22, 2022

(C) 2022 The Author(s)

\begin{abstract}
Sustainable practices aiming to reduce environmental impacts have become key guiding principles of events, but initiatives focusing on the economic impacts and on supporting the local economy and society are also gaining more emphasis in event planning and management. Music festivals attracting larger audiences are becoming especially aware of the importance of sustainability as well as of their role in the process of raising participants' awareness of it. The paper aims to assess the initiatives of the Street Music Festival in Veszprém, Hungary, one of the flagship events of the city, from both the participants' and the organisers' perspective. For the investigation of participant attitudes, a questionnaire survey was conducted, while the organisers' views on sustainability were sought through interviews. The findings show that although respondents rate the importance of sustainability as very high, their contribution to responsible consumption is far from what could be considered sustainable, therefore better communication of the initiatives or stricter rules need to be introduced. The interviewees revealed that organisers consider economic sustainability just as important as the environmental issues, and gave an insight into the rationale behind sustainability enhancing initiatives, some of which have a marketing function as well as protecting the environment.
\end{abstract}

\section{KEYWORDS}

sustainability, events, awareness raising, visitor attitude, European capital of culture

\section{INTRODUCTION}

Although sustainable practices aiming to reduce the negative environmental impacts have been prevalent at events for over a decade now (Mair - Laing 2012; Mair - Smith 2021), initiatives

\footnotetext{
*Corresponding author. E-mail: raffay.agnes@gtk.uni-pannon.hu
} 
focusing on the economic impacts as well as supporting the local economy and society are also gaining more emphasis in event planning and management (Moscardo 2008; Andersson et al. 2015; Perry et al. 2020). Getz (2010) points to the role festivals play in the regional development of an area. Studies by Mair and Laing (2013) and Ye et al. (2020) have established that music festivals attracting larger audiences are becoming especially aware of the importance of sustainability as well as of their role in the process of raising participants' awareness of it. There is a growing interest in the social impacts of festivals as well, assessing how they impact on the everyday life of residents (Theodorakis et al. 2015), and how events can strengthen local pride and patriotism and enhance community spirit (Formádi - Hunyadi 2019).

The paper aims to investigate the sustainability related initiatives of the Street Music Festival in Veszprém, Hungary, assessing the attitude of festival visitors to sustainability at festival, as well as the rationale behind the sustainability-focussed initiatives proposed by the organisers. The festival is part of Veszprém-Balaton 2023 European Capital of Culture (hereon in ECoC) Project, which places special emphasis on sustainability as one of three horizontal goals, which also include barrier-free and child-friendly programme development. The paper sets the scene first by discussing the three pillars of sustainability and presenting best practice examples of sustainability initiatives aiming to reduce the most common negative impacts and to promote responsible production and consumption at music festivals. Following this, the sustainability initiatives at the Street Music Festival will be analysed from both the participants' and the organisers' perspective.

The methodology is based on a questionnaire survey conducted during the festival in August 2020 assessing how participants rate the importance of sustainability measures and how they can contribute to sustainability. Semi-structured interviews conducted with the organisers provide further insight into the rationale behind their sustainable practices and awareness raising initiatives, as well as the challenges they face.

\section{LITERATURE REVIEW}

\subsection{Environmental, economic and social pillars of sustainability}

Sustainable practices aiming to reduce the negative environmental impacts have become key guiding principles of events (Mair - Laing 2012, Jones 2017). Besides the green practices, initiatives focusing on the economic impacts as well as supporting the local economy and society are also gaining more emphasis in event planning and management (Andersson et al. 2015).

2.1.1. Environmental sustainability. Although all three pillars of sustainability are equally important, the literature of sustainable events suggests that organisers put environmental considerations in the focus, trying to ensure the negative impacts caused by the event are reduced to a minimum, and quite often this effort is accompanied by the promotion of green actions and communicating the green aspects of the event. The rationale behind these considerations is easy to understand as the environmental impacts of (especially large-scale) events such as piles of litter or trampled on grass at festival sites are most visible. As Mair and Smith (2021) point out, in some research sustainability is often only concerned with environmental impacts, like Pernecky and Luck (2013), who refer to "the predominance of texts that assess environmental impacts and the need to green the events industry" (Mair - Smith 2021: 1740), 
and in research by Boggia et al. (2018) where the terms sustainability and environmental effects are used interchangeably. Based on the focus of sustainable practices, a distinction can be made between organisations implementing green actions and organisations committed to all three pillars of sustainability in their management and operations (Raj - Musgrave 2009; Mair - Jago 2010).

2.1.2. Economic sustainability. Besides the environmental aspects, organisers consider the economic ones as well, making sustainability equal to continuity, referring to guaranteed financial sources and income that ensures the event can be staged in the long run (Zifkos 2015). In the case of profit-oriented events, one of the key aims is to generate income as well as profit from the ticket sales and from sponsorship as well as fees the organisers can collect from service providers related to the event, such as rental fees of food stalls, etc. (Choi - Sirakaya 2006). However, economic sustainability has to be considered even in the case of non-fee-paying events as well, where the main objective of the event is other than generating revenue. As Getz (2010) argues, festivals are often featured in place marketing and tourism, therefore they can play an important role in regional development of the area that hosts them. He notes that economic development and impacts of events are frequent topics of articles focusing on event management and event tourism (Tang - Turco 2001; Moscardo 2008; Perry et al. 2020).

2.1.3. Social sustainability. There is a growing interest in researching the social impacts of the festivals, including how they impact on the everyday life of local residents and how they foster collaboration among various actors such as local residents, local NGOs and other stakeholders. Generally the music events bring enjoyment to the participants. A 'feel-good factor' refers to senses of feeling good, (communal) wellbeing and happiness as a result of participation. It is used alongside the term happiness, which can be defined as 'a condition of psychological balance and harmony' (Theodorakis et al. 2015). It is also noted that the events can lead to the strengthening of local pride and patriotism, and can enhance community spirit (Formádi Hunyadi 2019).

The social impacts are measured mainly in three areas which are strongly connected to each other:

- Locals' participation: the degree to which a festival stimulates locals' participation (e.g. how it is integrated into the yearly calendar of locals). It can be as participant or as volunteer.

- Attitudes and beliefs: the degree how the festival influences people's beliefs, attitudes, norms and values (e.g. pride, happiness, feeling good).

- Social cohesion and cooperation: social cohesion is the ongoing process of developing the local community of shared values, shared challenges and equal opportunities, based on a sense of trust, hope and reciprocity. Part of that the interaction occurs between individuals and stakeholders, e.g. local organisations, institutions, local businesses and entrepreneurs, local authorities. The event provides a platform to involve the community and strengthen social capital.

However, event organisers may encounter challenges in terms of implementing sustainable practices. Research by Mair and Laing (2012) concluded that besides the personal values of the festival organisers, the level of commitment of other stakeholders (local community, authorities, service providers, festival visitors, employees, performers, exhibitors, etc.) is also a decisive factor 
whether the festival is really staged in a sustainable way or not. It must also be mentioned that lack of time and financial sources are also among the hindering factors that jeopardize sustainable implementation (Mair - Laing 2012).

2.1.4. Building on all three pillars - striking a balance. Although it is generally accepted that the three pillars are equally important, it poses a great challenge to event organisers to find the right balance. Getz (2009) argued that the supposedly "new paradigm [of sustainable and responsible events] is generating increasing pressure for the application of a [Triple Bottom Line] approach in which both the worth and impacts of planned events are evaluated with balanced measures reflecting economic social/cultural and environmental considerations" (Getz 2009: 64). Getz (2017) and Mair (2019) suggest adopting a new perspective and argue that the focus should shift from the intention of trying to run "sustainable events" to the assessment of how events can contribute to the sustainable economic, social and environmental development of the places which host them (Mair - Smith 2021). For the purposes of this research, the authors adopt Mair's (2019) view on sustainable events as events that are key agents of fostering sustainable economic, social and environmental development in the host community.

2.1.5. Attitude of festival visitors to sustainability. The growing demand for sustainability on behalf of the participants has become a trend that facilitates, or even forces the implementation of sustainable principles at events (Ye et al. 2020). This demand can be traced back to the growing awareness of climate change and increasingly worrying lack of clear water and droughts in some places, and of extreme weather conditions that jeopardize the existence and staging of events.

Music festivals attracting larger audiences are becoming especially aware of the importance of sustainability as well as of their role in the process of raising participants' awareness of it (Mair - Laing 2013; Ye et al. 2020). Festival visitors may play a significant role in the realization of sustainable principles. An increasing number of research focuses on awareness raising techniques that target festival visitors and the efficiency of sustainability centred educational programmes taking place at events (Mair - Laing 2013; Efeja et al. 2016; Tolkes - Butzmann 2018). Mair and Laing (2013) concluded that primarily those visited green and sustainable festivals whose way of thinking is based on sustainability, therefore participating in such events served as a positive reinforcement of their way of thinking and lifestyle.

The majority of awareness raising initiatives focus on environmental sustainability of events, however, quite often an environmentally conscious solution also relates to economic and sociocultural factors. It is of utmost importance that awareness raising programmes are delivered in the spirit of edutainment to encourage visitor participation, for example through co-creation, joint search for solutions for sustainability related challenges, creative workshops, etc. (Efeja et al. 2016).

Not many people are aware what an enormous impact food has on the environment. Reports state that the food and agriculture sector is responsible for a significant proportion (around $25 \%$ ) of global greenhouse gas emissions. Due to environmental concerns and a growing awareness of healthy lifestyle, eating habits have changed significantly in the 21st century. A reduction of certain food products, such as meat and dairy products, can be observed parallel with the growth of other types of products, such as vegetables, plant based drink, gluten free products. The growing demand for special diets has also got its roots in the growth of the 
proportion of people suffering from certain food allergies or intolerances (Benedé et al. 2016). More and more festivals recognise the need as well as the business potential in providing catering options to satisfy the needs of visitors with special dietary needs and preferences (van Berkel 2014; Raffay-Danyi - Ernszt 2021). Besides the aim of serving a wider ranges of customers, providing environmentally healthy food, and sourcing them from ethical producers also serves the aspirations of festival organisers to become more sustainable. The Good Food Guide for Festivals (2012) compiled by the not-for profit organisation A Greener Festival, in cooperation with the Food Legacy programme and the Ethical Eats project, supports festival organisers in achieving their aims.

\subsection{Initiatives aiming at enhancing sustainability at events}

Most of the sustainability initiatives at festivals tend to focus on the environment, aiming to reduce and mitigate the potential negative impacts of the event (Paton - McCullen 2014). Research by Maung (2010) points out that for example at Glastonbury alone 54 tonnes of cans and plastic bottles, 9.12 tonnes of glass, 11.2 tonnes of tents and 193 tonnes of compostable material including food and paper cups were left behind in 2009. Waste reduction is a key concern, which can manifest in various forms, like in reducing the amount of rubbish generated at festivals and reducing the use of plastic wherever it is possible. Although it is possible to recycle plastic bottles, and even reuse them, by far the best option is not to have a disposable bottle at all. Many festivals aim to provide drinking water so that participants refill their own flasks and bottles instead of buying bottled water. In 2011, Limetree Festival in the United Kingdom set the target to go entirely plastic-free during the whole event, bottled water was not available at all, and with the help of Tapwater.org free tap water was made available on the festival site (Limetree Festival 2020). A similar initiative at Glastonbury Festival introduced in 2019 was described by Marsh (2019). Removing straws from festivals is also getting very common, and although some vendors still offer straws with drinks participants are encouraged not to ask for straws (for example at the Sziget Festival in Hungary), and the use of alternative cutlery and plates, as well as reusable glasses were also common initiatives. However, in 2020, single use items were encouraged once again to avoid the spread of Coronavirus, so this process has come to a, hopefully only temporary, halt.

Where the massive use of plastic (and other recyclable items such as glass or cans) cannot be avoided, recycling bins and points were installed to ensure that certain items get recycled and get a new life instead of ending up as landfill waste. It has become common practice at festivals to find various ways of encouraging festival goers to collect their recyclable items and dispose of them in the appropriate way and place. Many festivals exchange recycling for useful souvenirs such as free WIFI, $t$-shirts, rain poncho, etc. in a well worked out system where every item of recycling has a certain value (e.g. 15 cans for a rain poncho).

Other initiatives originating from environmental concerns address the issue of $\mathrm{CO}_{2}$ emissions. Gray (2013) lists transport as a key damaging effect on the environment in case of festivals, while Atkinson (2010) points out that festival goers travelling to and from the festival site create the largest component of the impact. The most noticeable efforts manifest in encouraging visitors to use environmentally friendly modes of transport when approaching the festival site. For example, as one of the world's largest outdoor music festivals, Glastonbury Festival is totally committed to reducing carbon emissions and to raising awareness of what can be done to help 
combat climate change. In this spirit, those arriving to the festival by public transport or bicycle are given a Green Traveller lanyard, which entitles them to get discounts on main meals and a festival t-shirt, and access to solar showers. Similarly, the Sziget Festival in Hungary also encourages participants to use bicycles between the festival site and the city centre, and provide a safe bicycle locker by one of the bridges of the island that serves as the festival venue.

Offering $\mathrm{CO}_{2}$ friendly food is also a small but significant step towards reducing $\mathrm{CO}_{2}$ emissions. The environmental considerations meet the trend of growing demand for more healthconscious dietary options, and to accommodate the demand for vegetarian and vegan dishes, some festival organisers started to rethink the food offer at their festivals by reducing or even removing meat from the offer. The Sziget Festival recommends festival goers to try some of the $\mathrm{CO}_{2}$ friendly delicacies at the Mama Earth Eatery, while DGTL Festival in the Netherlands has completely removed meat from the menu, which as they claim has reduced $\mathrm{CO}_{2}$ emissions and saved large amounts of freshwater and land (DGTL 2020; van Berkel 2014).

Some festivals are also concerned about the social impacts events can have on the local community as well as festival goers. It can manifest in the promotion of local, organic and fairtrade products at the events, such as the Sunrise Festival in the United Kingdom, where the organisers have established a site-wide organic policy for all food and drinks, including alcohol, and encouraged traders to use local suppliers - which also aims to minimise the environmental cost of transporting goods (The Good Food for Festivals Guide 2012).

Social impacts can also be addressed by presentations on climate change issues, environmental protection. As part of the Love Revolution campaign launched by the Sziget Festival in 2017, Jane Goodall, the world-renowned ethologist and United Nations Messenger of Peace, held a presentation on the main stage at the Sziget Festival to draw attention to the importance of respecting human rights and protecting the environment. A Dutch example is presented by van Berkel (2014), describing Lab Vlieland Festival's initiative to involve festival goers, students and progressive manufacturers into a think-tank where creative sustainable ideas for dealing with energy and (re)using resources at festivals are discussed.

\section{PLACE OF THE VESZPRÉM STREET MUSIC FESTIVAL IN THE HUNGARIAN MUSIC FESTIVAL LANDSCAPE}

Hungary has a well-established place in the European pop music festival circuit, largely due to the Sziget Festival which attracts a significant international audience to Budapest every year. Some other festivals have a significant place in the Hungarian festival calendar, such as Balaton Sound (one of the largest electronic music festival in Europe) hosted in Zamárdi until 2019 (the festival will move to a different site in 2022), the Telekom Volt Festival in Sopron, the Campus Festival in Debrecen and the EFOTT by Lake Velence, just to name some of the most popular ones. These festival are fee paying events, staged in fenced off festival sites, mostly campsites.

Unlike these festivals, the Veszprém Street Music Festival takes place on the open streets of the historic city centre of Veszprém, and is a free event that has entertained tens of thousands of visitors a year since 2000. The event is staged in the third week of July from Wednesday to Saturday, when from mid-afternoon until early evening previously selected street musicians compete for the professional award and the audience prize, while late in the evening they are followed by international artists and acknowledged Hungarian street musicians. 
Since 2015, the Street Music Festival has been accompanied by a gastronomic event as well, the Food Truck Show, which first appeared outside of Budapest in Veszprém. The Food Truck Show aims to present mobile food trucks serving high quality dishes and drinks in a short period of time and concentrated to a reasonably small area. Festival visitors can enjoy craft beer and juices, spirits and wines and food produced from a varied range of ingredients.

Until 2020, the festival also offered various additional activities. A ferriswheel towering above the Óváros Square of the town offered extra entertainment one year; for many years fun and environmental awareness raising activities were organised for kids and families by the local communal services provider in association with the festival organisers, and the University of Pannonia was also present with games to entertain the audience. In 2020, due to the COVID-19 pandemic, the staging of the event remained an open question until the last minute. Although with a significantly reduced content, the Street Music Festival and the Food Truck show was staged at the end of August, complying with the strict pandemic regulations. Twenty street musicians entertained the audience on four stages, the reduced programme concentrated only to the main hub, Óváros Square and the surrounding streets.

Since 2020, the Street Music Festival is part of the Veszprém-Balaton 2023 European Capital of Culture project, which has put sustainability as a key guiding principle on their flag. The programmes organised under the umbrella of the ECoC project are encouraged and supported to implement sustainability goals. Even though sustainability is not a new concept for the organisers of the Veszprém Street Music Festival, the special emphasis on sustainability related to joining the ECoC project provided the key motivation for conducting the research on sustainability awareness at this event.

\section{METHODOLOGY}

The current research aims to assess participants' attitude to sustainability as well as their consumption at the Veszprém Street Music Festival, and also the rationale behind the sustainability-focused initiatives proposed by the organisers. The study seeks answers to the following research questions:

Q1: How important do festival visitors rate sustainability measures?

Q2: To what extent is the visitors' consumption at the festival site sustainable?

Q3: What does the concept of sustainability mean to the organisers?

Q4: What kind of initiatives have the organisers introduced and with what intention?

Within the framework of a project focusing on circular economy and aiming to investigate the sustainability issues of festivals, a questionnaire survey was conducted during the Street Music Festival in Veszprém in 2020. The respondents were chosen randomly at the festival site where festival volunteers recorded responses on the paper-based questionnaires during the four days of the event, and the questionnaire was also available online on the www. veszprembalaton2023.hu website. The questionnaire was developed within the framework of the above mentioned project specifically for events, primarily to assess visitor attitude towards sustainability at events organised or supported by the Veszprém-Balaton 2023 European Capital of Culture project. 
The questionnaire contained demographics related questions to assess the profile of the festival goers, and specific questions regarding mainly the environmental and socio-cultural pillars of sustainability, impacts of events, as well as sustainable consumption, with special emphasis on food and drink consumption, based on the key findings of the literature on potential impacts of events, behaviour of event visitors, sustainable festivals and visitor attitudes towards festival sustainability. Environmental sustainability was measured with indicators such as means of transportation used and distance travelled by the visitors to the festival, and by attitude statements to outline the visitors' food and meat consumption during the festival as well as their attitude towards recycling and access to drinking water. Socio-cultural sustainability was addressed with attitude questions aiming to map the visitors' interest in the local characteristics of the festival, and to investigate how important the event is for them as a social gathering and how much they are attached to the festival. Furthermore, a set of statements about general sustainability issues aimed to assess how these are perceived at the Veszprém Street Music Festival. An even number (4 points and 10 points) Likert-scale was used to measure the attitudes regarding the various issues of sustainability. Altogether 403 participants' responses were evaluated. Furthermore, interviews were conducted with the two organisers of the festival to provide further insight into the rationale behind their sustainable practices and awareness raising initiatives, and to establish the challenges they face in terms of sustainable implementation of their event.

\section{RESULTS}

\subsection{Results of the questionnaire survey}

The Veszprém Street Music Festival attracts young and middle-aged people primarily, the majority of the respondents were between 18 and $49,55 \%$ of the respondents were female and $45 \%$ male. Almost half of the respondents have higher education qualification, and a further $35 \%$ have completed secondary education. As Fig. 1 depicts, the respondents are mostly local, $24 \%$ live either in Veszprém or close by, $45 \%$ within $10 \mathrm{~km}$ from the city, and only $4 \%$ of the participants have arrived to the festival from more than $200 \mathrm{~km}$. The average distance travelled is $44.6 \mathrm{~km}$.

The sustainable production and consumption related questions focused on food and beverage consumption, specifically also about tap water consumption, on waste recycling, on interest in the local character of the event and on the potential sustainability issues that need addressing.

The first food related questions aimed to map the respondents' dietary preferences on average weekdays and during the festival. As Fig. 2 shows, there are hardly any differences between the eating habits of the two scenarios, and most of the respondents have a mixed diet. The proportion of those eating reduced amounts of meat is between 6 and $8 \%$, and $10 \%$ of the participants consume meat with every meal, while the proportion of the vegan and vegetarian respondents is just a few percent in the overall sample, which equals to 6 and 7 people respectively.

The survey also aimed to assess how often participants buy food products to consume at the festival site. The results show that a quarter of the respondents does not but any food at all, while a third of them have one smaller meal (snack) and one main meal during the festival. 


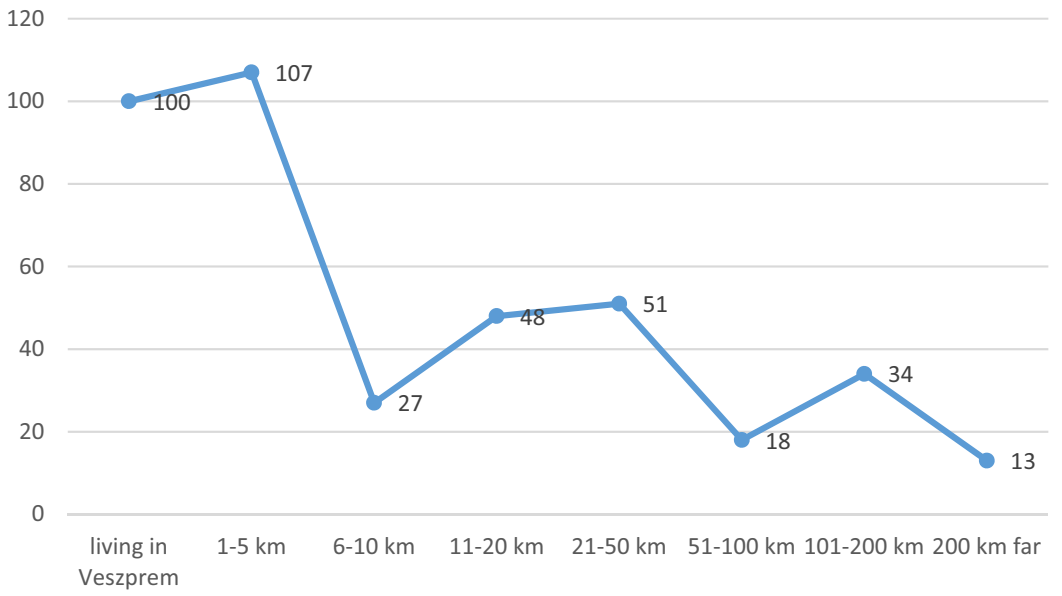

Fig. 1. Festival visitors' place of residence (number of persons)

Source: authors.

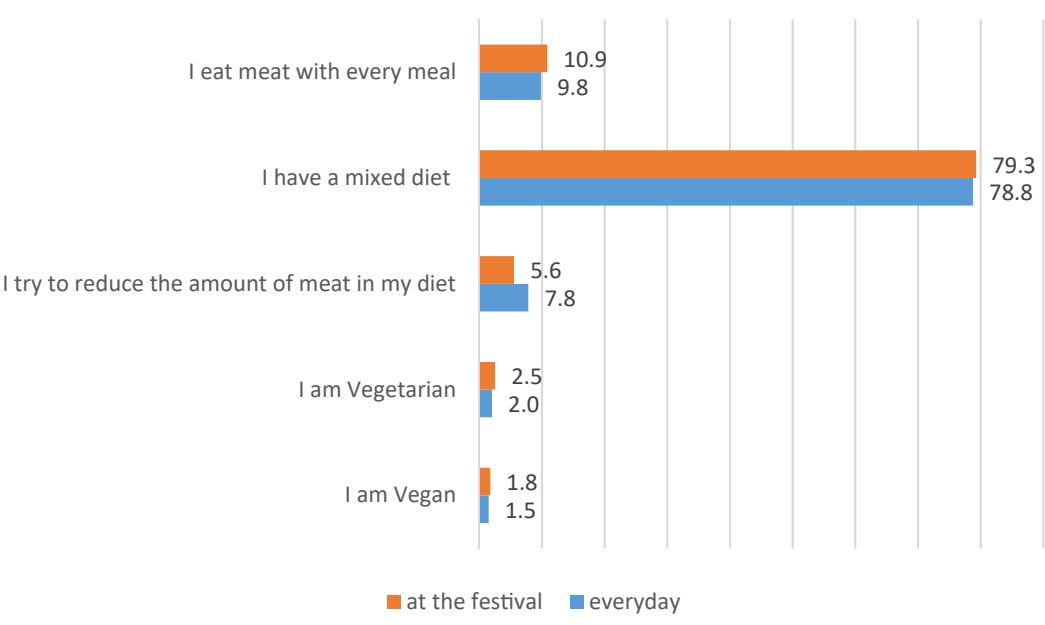

Fig. 2. Dietary preferences of festival visitors (\%)

Source: authors.

The survey revealed that $15.2 \%$ of the respondents have some sort of food allergy. When asked to what extent respondents were satisfied with the range of food on offer in relation to their preferences, the average response was 3.2 on a scale of 1-4 where 4 is completely satisfied. However, respondents indicating a vegan diet were less lucky to find a suitable offer during the event. Figure 3 indicates the average responses according to the different food preferences/diet of respondents.

The majority of the respondents consider it very important to have tap water available at the festival (Fig. 4), rating it 3.3 on a scale of $1-4$, where 4 is very important. 


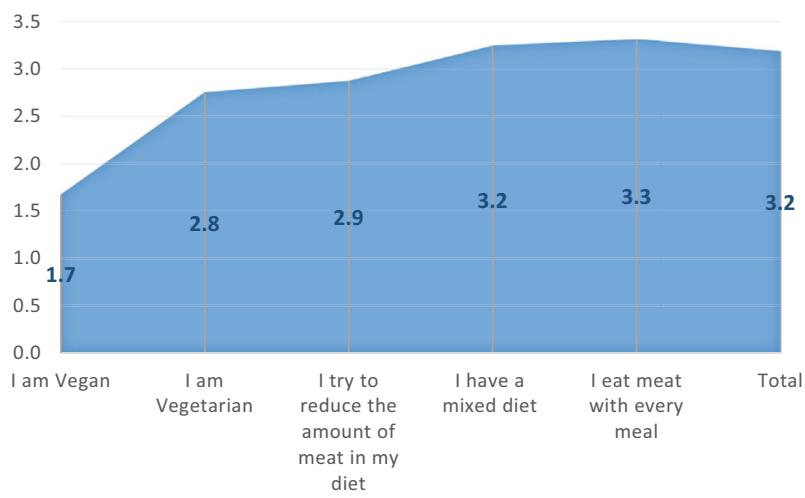

Fig. 3. Satisfaction with the food offer at the Veszprém Street Music Festival Source: authors.

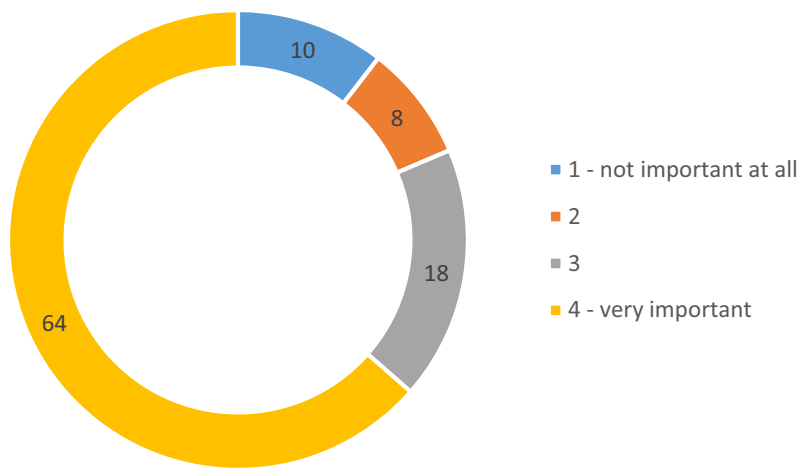

Fig. 4. Importance of available drinking water at the Veszprém Street Music Festival Source: authors.

However, only a third of the participants declared that they refill their flasks at the festival site, while $41 \%$ buy bottled water. This finding indicates a significant gap between the attitude and the action of festival visitors, as even though they consider it important to have access to drinking water at the festival site, the majority still opts for bottled water. Those buying bottled water would purchase 1.8 bottles on average ( $80 \%$ suggested buying one or two bottles). Participants under 18 are most environmentally conscious, they are more likely to refill their flasks, but there was no difference to be detected in case of gender or educational qualification of the respondents in terms of buying bottles or refilling flasks.

The question of buying bottled water relates to the amount of waste produced as well as recycling. Respondents were asked whether they had come across recycling containers at the festival site and if so, had they used them. More than $67 \%$ of the respondents had noticed the recycling bins, and 53\% of the participants had already used them, and 32\% of them claimed they would use them once necessary but it was not the case thus far (Fig. 5). In general, $80 \%$ of 

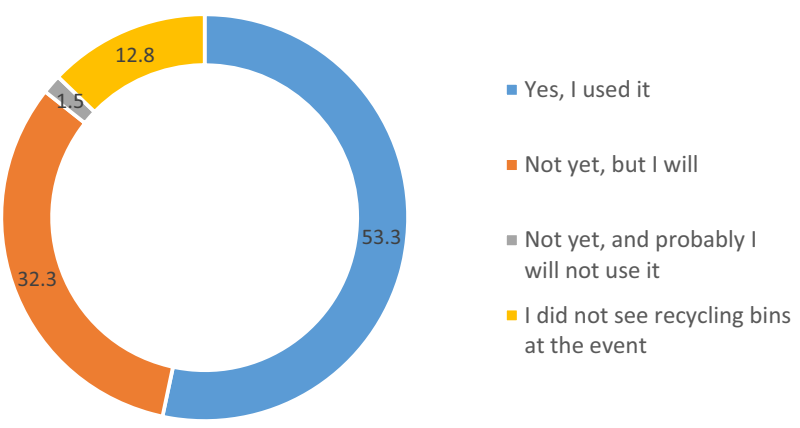

Fig. 5. Use of recycling bins at the festival Source: authors.

the festival goers argued that it is very important to ensure recycling at a festival site, the average response rate was 3.8 on a scale of $1-4$, where 4 is very important.

The survey also aimed to assess some of the social impacts of festivals. Various questions were posed to map if the participants were interested in local programmes, local customs, local attractions, local crafts produce, local food and the lifestyle of the local people (Fig. 6). As the survey was conducted at a music festival, not too surprisingly respondents were mostly interested in local programmes, $57 \%$ of them indicated they were very interested, local attractions were the second most popular item on their list ( $45 \%$ marked these as very important for them), while participants are least interested in the lifestyle of the local people $(20 \%$ of them were not interested at all). This indicates that festival visitors at the Veszprém Street Music Festival are less committed to the socio-cultural pillar of sustainability, as they are less interested in some of the factors through which the festival may have a positive social impact on the local residents' everyday life.

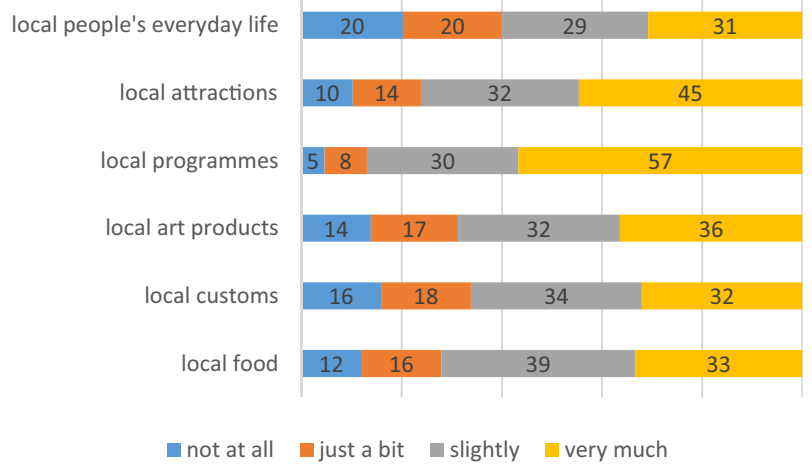

Fig. 6. Level of interest in the local characteristics of the festival (\%)

Source: authors. 
One of the complex questions was designed to assess the perceptions of respondents regarding certain selected sustainability issues. Respondents had to rate them on a scale of 1-4 where 1 indicates these issues are not present at all at the festival, and 4 means they cause significant problems. As Fig. 7 indicates, the use of single use plastic was perceived as the most significant problem, however it must be reinforced that the survey was conducted during the COVID-19 pandemic, when single use items were reintroduced in many places to minimise the risk of contamination. Interestingly, the issue of noise was perceived as the least of the problems, even though the participants of a music festival formed the audience of the survey.

We used data reduction, specifically principal component analysis, to highlight the latent correlations between the perceived problems. We managed to elaborate two main factors: one major factor relates to the waste problems (including the garbage problem, use of throw-away plastic products), the second group relates to traffic and parking related sustainability problems.

The questionnaire also contained a question about the importance of the sustainability of the festival. Respondents could rate the importance of sustainability on a 1 to 10 scale where 10 indicated high importance. $45 \%$ of the participant rated it 10 out of 10 , and 8.8 was the overall average of the responses. The respondents over the age of 50 rated it higher than the average (9.2), and those with lower educational qualification indicated slightly lower rates for importance than the average (8.4).

One of the most significant social impacts of the Veszprém Street Music Festival is that is creates an opportunity to meet up and hang out with friends, therefore as an added value it also helps to strengthen relationships. It plays an important social role in the annual calendar of the local residents, they are looking forward to participating in it and have strong attachment to the festival. The bonding index is 7.7 (average) on a 1 to 10 scale, and the closer the respondents live to the festival, the stronger their attachment is to the festival. Furthermore, the more attached respondents are to the festival, the more important they rate sustainability at the event.

\subsection{Interview findings}

As the coin has two sides, it was important to investigate what constitutes sustainability for the organisers and what considerations led to the sustainability enhancing initiatives and measures that visitors could experience at the Veszprém Street Music Festival.

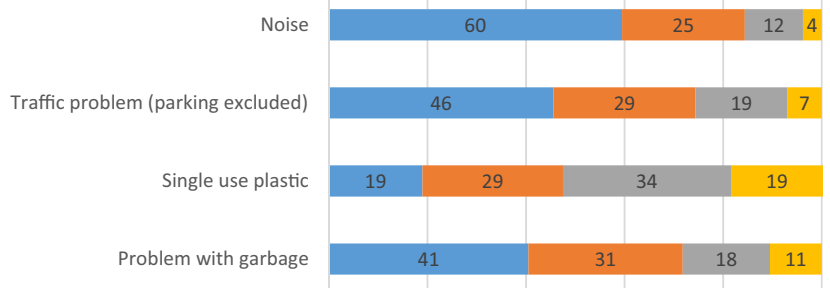

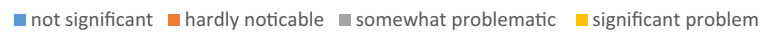

Fig. 7. Perceived sustainability problems at the Veszprém Street Music Festival (\%) Source: authors. 
The interviews with the organisers of the festival revealed that all three aspects of sustainability must be considered. The main organiser of the event referred to the long-term viability of the festival as an indicator of sustainability: "It is sustainable if it is financially sustainable as well, if it can operate in the long run. If you do something only once or twice, it takes more energy altogether than running the festival for years, so you leave a bigger ecological footprint. You need to achieve that there is demand for the festival, then it becomes sustainable." The other person in charge of organisation referred to environmental and the social pillars of sustainability primarily, claiming that a festival can be considered sustainable if it does not leave a trace on the environment, so the environmentally friendly activities are most important, but it must be good for the people as well. Both respondents emphasised the advantages of sustainable implementation of events. "One of the great advantages of sustainable events is that they are more likeable for the audience. It is a sort of requirement now from festival goers, so being sustainable may create a competitive advantage." This was confirmed by the respondents of the questionnaire survey, who rated the importance of sustainability 8.8 on a 1 to 10 scale where 10 indicated high importance. Sustainability has a strong image building role. "First it was only trendy to be green or sustainable, nowadays it is embarrassing if you are not. Also, if an event is viable (economically sustainable), you can attract more sponsors as well. If you operate in the long run, you can learn from your mistakes."

When asked about actions to reduce waste, the responses were referring to the good collaboration with the local communal service provider, which is responsible for collecting and removing litter during the night, "so by 6am there are no traces of the party the night before." To tackle the problem of waste management, recycling bins were also introduced at the festival. Interestingly, roughly a third of the festival goers did not notice the recycling bins at the festival site, but the majority of the respondents $(80 \%)$ considered it very important to ensure recycling at the festival. However, both organisers hinted at the obstacles that hindered them in being more environmentally friendly, partially due to the coronavirus pandemic "We have operated with reusable glasses before but unfortunately we had to reinstate plastic cups because of COVID-19 so it is a step back unfortunately." This was reflected in the questionnaire survey results as well, the respondents identified single use plastic as the most significant sustainability problem. The organisers also pointed out that it is an open festival, not controlled by barriers or fences: "Litter collection is also a difficult question, as the festival normally uses the whole city centre, therefore we cannot stop people from throwing litter away." Furthermore, the latter circumstance also jeopardises enforcing sustainable initiatives such as avoiding the use of plastic: "As it is an open festival (staged in an open space), we cannot force anything on the service providers.

The organisers are keen on providing drinking water and refilling bottles. They have designated a drinking water tap in the Castle area but they acknowledged that there is need for more refilling points at the festival site. This initiative seemed to have little impact on the visitors' attitude as $41 \%$ of the survey respondents claimed to have bought bottled water.

As for awareness raising educational programmes, the organisers used to cooperate with the local communal service provider company and the University of Pannonia to run programmes, primarily for children. Although these were successful based on the feedback from the participants, such activities did not get incorporated into the 2020 programme due to the strict regulations, especially regarding limited visitor numbers.

The Street Music Festival places significant emphasis on the gastronomical offer. Although defining the concrete range of food and drinks in beyond the competence of the festival 
organisers, they have defined taking the food preferences and needs into consideration: serving a wider audience is one of the requirements towards the service providers. As food allergy is a key problem of our age, everyone has to pay attention to it. "There is a growing demand to serve the needs of visitors with special dietary requirements. Furthermore, as you can sell such products at higher prices, the market is also motivated to satisfy the special needs. The communication of every event has to emphasise the options they offer to vegetarians, vegans and people with food allergies or intolerances." Admittedly, it is also trendy to have vegan food on offer so they are aiming to attract a vegan truck every year. They have also confessed that from the organisers' point of view it is easier to select catering providers that specialise on certain diets than prescribing to each and every service provider to respond to special needs as well. The efforts to find the right dietary solutions for a wide range of the audience seems to have paid off: respondents were satisfied with the food offer at the festival, rating the satisfaction 3.2 on a scale of 1-4. Vegan respondents were less pleased with the range of food, rating the offer 1.7, but their proportion at the festival was very low so these responses do not reflect the views of most festival visitors.

\section{CONCLUSIONS AND FUTURE RESEARCH DIRECTIONS}

Based on the results, it can be concluded that 'we are not there yet', audience awareness does not yet translate into action at the Veszprém Street Music Festival. The findings of the survey showed that although visitors rate the importance of sustainability as very high, their contribution to responsible consumption is far from what could be considered sustainable. The most striking gap between awareness and action relates to water consumption: although the majority of the respondents consider it very important to have tap water available at the festival, only a third of the participants refill their flasks at the festival site, while $41 \%$ buy bottled water. As for food consumption habits, even though the organisers place emphasis on providing meet free options, there is no significant demand for meet free food, only a minority of respondents follows a vegan or vegetarian diet, and reduced meet consumption is not typical at all. Based on these findings, the festival food trends discussed in the literature review are not prevalent at the Veszprém Street Music Festival. Furthermore, visitors of the Veszprém Street Music Festival are less interested in the local character of the festival, the respondents indicated only low level of interest in local arts, and local people's habits and lifestyle. The picture is more positive in the case of waste reduction and recycling: more than $67 \%$ of the respondents had noticed the recycling containers placed at regular intervals at the festival site, 53\% of the participants had used them, and $32 \%$ of them would use them later during the event. In general, $80 \%$ of the festival goers argue that it is very important to ensure recycling at a festival site, the average response rate was 3.8 on a scale of $1-4$, where 4 is very important.

The interviewees revealed the rationale behind their sustainability enhancing initiatives and pointed out the challenges that influence the implementation of these. The restrictions imposed by the COVID-19 pandemic were regarded as the greatest challenge, on the one hand related to visitor numbers and with that the significantly reduced range of programmes, and on the other hand the introduction of single use items in order to avoid potential contamination. Furthermore, the organisers referred to the lack of power to impose sustainability measures on the service providers as the festival takes place in the open streets of the city centre and it is beyond 
their control what the service providers do who are not part of the Food Truck Show offer. A way forward would be to empower the organisers to control sustainable production, which in turn may also foster more sustainable consumption as well.

The results imply that the concept of sustainability is important to festival visitors, however, only a few initiatives are successful and are reflected in the attitude and actions of visitors (such as using recycling bins), others are unnoticed or do not create the intended effect (such as using tap water). It points to the need for better communication, to ensure that the initiatives are visible to festival goers and their awareness is raised. The limitations of the current research include that it assesses only the attitude of visitors towards sustainability; it would be worth comparing this with the attitude of the service providers as well. Furthermore, the analysis was conducted during the COVID-19 pandemic which made the implementation of certain sustainability measures rather difficult, therefore it would be worth repeating the research when the Street Music Festival is back to the normal. The authors plan to conduct a similar research in the coming years to monitor whether the awareness and the attitude of festival visitors is changing over time, and also to assess whether new initiatives and sustainability measures are introduced. Furthermore, a comparison with other festivals would also be beneficial to gain a better understanding of festival goers' attitude towards sustainability at music festivals.

\section{ACKNOWLEDGEMENT}

The research has been supported by the National Research, Development and Innovation Fund of Hungary, financed under the project no. 2019-1.3.1-KK-2019-00015, titled "Establishment of a circular economy-based sustainability competence center at the University of Pannonia".

\section{REFERENCES}

A Greener Festival (2020): A Greener Festival https://www.agreenerfestival.com, accessed 10/08/2020.

Andersson, T. D. - Armbrecht, J. - Lundberg, E. (2015): Linking Event Quality to Economic Impact: A Study of Quality, Satisfaction, use Value and Expenditure at a Music Festival. Journal of Vacation Marketing 23(2): 114-132. https://doi.org/10.1177/1356766715615913.

Atkinson, S. (2010): Festivals Put Green Issues Higher up the Bill. BBC News Business. https://www.bbc. com/news/10145690, accessed 21/10/2021.

Benedé, S. - Blázquez, A. B. - Chiang, D. - Tordesillas, L. - Berin, M.C. (2016): The Rise of Food Allergy:

Environmental Factors and Emerging Treatments. EBioMedicine 7: 27-34. https://doi.org/10.1016/j. ebiom.2016.04.012.

Boggia, A. - Massei, G. - Paolotti, L. - Rocchi, L. - Schiavi, F. (2018): A Model for Measuring the Environmental Sustainability of Events. Journal of Environmental Management 206: 836-845. https:// doi.org/10.1016/j.jenvman.2017.11.057.

Choi, H. C. - Sirakaya, E. (2006): Sustainability Indicators for Managing Community Tourism. Tourism

Management 27: 1274-1289. https://doi.org/10.1016/j.tourman.2005.05.018.

DGTL (2020): DGTL Festival Amsterdam. https://dgtl.nl, accessed 14/09/2020. 
Efeja, L. - Kalach, A. - Krastina, S. - Olesen, G. B. - Petersone, A. - Szoleczky, J. - Usca, M. - Vaskovich, D. (2016): Decarbonize Our Future Guidelines Organizing Climate-friendly Events. https://www.inforse. org/europe/pdfs/PUB_Event_Guidelines_EN_2016_print.pdf, accessed 14/09/2020.

Formádi, K. - Hunyadi, Z. (2019): Helyi büszkeség vagy bosszúság?! A fesztiválok hatása a települések életében [Local Pride or Nuisance? The Impact of Festivals on Life in Settlements]. Prosperitas 6(4): 95111. https://doi.org/10.31570/Prosp_2019_04_6.

Getz, D. (2009): Policy for Sustainable and Responsible Festivals and Events: Institutionalization of a New Paradigm. Journal of Policy Research in Tourism, Leisure and Events 1: 61-78. https://doi.org/10.1080/ 19407960802703524.

Getz, D. (2010): The Nature and Scope of Festival Studies. International Journal of Event Management Research 5(1): 1-47.

Getz, D. (2017): Developing a Framework for Sustainable Event Cities. Event Management 21(5): 575-591. https://doi.org/10.3727/152599517X15053272359031.

Jones, M. (2017): Sustainable Event Management: A Practical Guide. Abingdon: Routledge.

Gray, L (2013): Glastonbury 2013: How Green Is Going to a Festival? The Telegraph. https://www.telegraph. co.uk/culture/glastonbury/10127604/Glastonbury-2013-How-green-is-going-to-a-festival.html, accessed 21/10/2021.

Limetree Festival (2020): Limetree Festival. https://www.limetreefestival.co.uk/, accessed 02/10/2020.

Mair, J. (2019): Rethinking event sustainability. In: Armbrecht, J. - Lundberg, E. - Andersson, T. (eds): A Research Agenda for Event Management. Edward Elgar Publishing.

Mair, J. - Jago, J. (2010): The Development of a Conceptual Model of Greening in the Business Events Tourism Sector. Journal of Sustainable Tourism 18(1): 77-94. https://doi.org/10.1080/09669580903291007.

Mair, J. - Laing, J. (2012): The Greening of Music Festivals: Motivations, Barriers and Outcomes. Applying the Mair and Jago Model. Journal of Sustainable Tourism 20(5): 683-700. https://doi.org/10.1080/ 09669582.2011.636819.

Mair, J. - Laing, J. (2013): Encouraging Pro-Environmental Behaviour: The Role of Sustainability-Focused Events. Journal of Sustainable Tourism 21(8): 1113-1128. https://doi.org/10.1080/09669582.2012. 756494.

Mair, J. - Smith, A. (2021): Events and Sustainability: Why Making Events More Sustainable is not Enough. Journal of Sustainable Tourism 29(11-12): 1739-1755. https://doi.org/10.1080/09669582.2021.1942480.

Marsh, S. (2019): Glastonbury Festival Bans Plastic Bottles. The Guardian. https://www.theguardian.com/ music/2019/feb/27/glastonbury-festival-bans-plastic-bottles, accessed 21/10/2021.

Maung, Z. (2010): Is the Litter-Free Music Festival Just Around the Corner? The Guardian. https://www. theguardian.com/environment/green-living-blog/2010/jul/02/glastonbury-litter-reusable-cupsrecycled-tents, accessed 21/10/2021.

Moscardo, G. (2008): Analyzing the Role of Festivals and Events in Regional Development. Event Management 11(1-2): 23-32. https://doi.org/10.3727/152599508783943255.

Paton, A. - McCullen, P. (2014): What Effects do UK Music Festivals have on the Environment \& How Can They Become More Environmentally Friendly? cris.brighton.ac.uk/ws/portalfiles/portal/476990/ McCullen+TPPP+ paper.pdf, accessed 21/10/2021.

Pernecky, T. - Luck, M. (2013): Events in the age of sustainability. In: Pernecky T. - Luck, M. (eds.): Events, Society and Sustainability: Critical and Contemporary Approaches. Abingdon: Routledge, pp. 1-12.

Perry, B. - Ager, L. - Sitas, R. (2020): Cultural Heritage Entanglements: Festivals as Integrative Sites for Sustainable Urban Development. International Journal of Heritage Studies 26(6): 603-618. https://doi. org/10.1080/13527258.2019.1578987. 
Raffay-Danyi, Á. - Ernszt, I. (2021): Esélyegyenlőség a Veszprém-Balaton 2023 Európa Kulturális Fővárosa projekt rendezvényein [Equal Opportunities on the Events of the Veszprém-Balaton 2023 European Capital of Culture Project]. Turisztikai és Vidékfejlesztési Tanulmányok 8(1): 5-19. https://doi.org/10. 15170/TVT.2021.06.01.01.

Raj, R. - Musgrave, J. (2009): Event Management and Sustainability. Oxfordshire: CAB International.

Tang, Q. - Turco, D. M. (2001): Spending Behaviors of Event Tourists. Journal of Convention \& Event Tourism 3(2): 33-40. https://doi.org/10.1300/J143v03n02_04.

The Good Food for Festivals Guide (2012): The Good Food for Festivals Guide. https://www.sustainweb. org/publications/good_food_for_festivals_guide/, accessed 12/05/2021.

Theodorakis, N. D. - Kaplanidou, K. - Karabaxoglou, I. (2015): Effect of Event Service Quality and Satisfaction on Happiness Among Runners of a Recurring Sport Event. Leisure Sciences 3(1): 87-107. https://doi.org/1080/01490400.2014.938846.

Tolkes, C. - Butzmann, E. (2018): Motivating Pro-Sustainable Behavior: The Potential of Green Events-a Case-Study from the Munich Street Life Festival. Sustainability 10(10): 1-15.

van Berkel, F. (2014): Researching Environmental Sustainability at Music Festivals. A Dutch Case. Master Thesis Project. https://doi.org/10.13140/RG.2.2.12549.58084.

Zifkos, G. (2015): Sustainability Everywhere: Problematising the Sustainable Festival Phenomenon. Tourism Planning \& Development 12(1): 6-19. https://doi.org/10.1080/21568316.2014.960600.

Ye, Y. - Su, C. H. - Tsai, C.H. - Hung, J. L. (2020): Motivators of Attendance at Eco-friendly Events. Journal of Convention \& Event Tourism 21(5): 417-437. https://doi.org/10.1080/15470148.2020. 1776656.

Open Access. This is an open-access article distributed under the terms of the Creative Commons Attribution 4.0 International License (https://creativecommons.org/licenses/by/4.0/), which permits unrestricted use, distribution, and reproduction in any medium, provided the original author and source are credited, a link to the CC License is provided, and changes - if any - are indicated. (SID_1) 